\title{
Design of Potent Membrane Fusion Inhibitors against SARS- CoV-2, an Emerging Coronavirus with High Fusogenic Activity
}

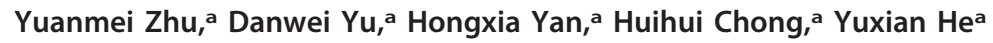 \\ aNHC Key Laboratory of Systems Biology of Pathogens, Institute of Pathogen Biology, Chinese Academy of Medical Sciences and Peking Union Medical College, Beijing, \\ China
}

Yuanmei Zhu and Danwei Yu contributed equally to this work. Author order was determined both alphabetically and in order of increasing seniority.

ABSTRACT The 2019 coronavirus disease (COVID-19), caused by the emerging severe acute respiratory syndrome coronavirus 2 (SARS-CoV-2), has posed serious threats to global public health and economic and social stabilities, calling for the prompt development of therapeutics and prophylactics. In this study, we first verified that SARS-CoV-2 uses human angiotensin-converting enzyme 2 (ACE2) as a cell receptor and that its spike $(S)$ protein mediates high membrane fusion activity. The heptad repeat 1 (HR1) sequence in the S2 fusion protein of SARS-CoV-2 possesses markedly increased $\alpha$-helicity and thermostability, as well as a higher binding affinity with its corresponding heptad repeat 2 (HR2) site, than the HR1 sequence in S2 of severe acute respiratory syndrome coronavirus (SARS-CoV). Then, we designed an HR2 sequence-based lipopeptide fusion inhibitor, termed IPB02, which showed highly potent activities in inhibiting SARS-CoV-2 S protein-mediated cell-cell fusion and pseudovirus transduction. IPBO2 also inhibited the SARS-CoV pseudovirus efficiently. Moreover, the structure-activity relationship (SAR) of IPB02 was characterized with a panel of truncated lipopeptides, revealing the amino acid motifs critical for its binding and antiviral capacities. Therefore, the results presented here provide important information for understanding the entry pathway of SARS-CoV-2 and the design of antivirals that target the membrane fusion step.

IMPORTANCE The COVID-19 pandemic, caused by SARS-CoV-2, presents a serious global public health emergency in urgent need of prophylactic and therapeutic interventions. The $\mathrm{S}$ protein of coronaviruses mediates viral receptor binding and membrane fusion, thus being considered a critical target for antivirals. Herein, we report that the SARS-CoV-2 S protein has evolved a high level of activity to mediate cell-cell fusion, significantly differing from the $S$ protein of SARS-CoV that emerged previously. The HR1 sequence in the fusion protein of SARS-CoV-2 adopts a much higher helical stability than the HR1 sequence in the fusion protein of SARS-CoV and can interact with the HR2 site to form a six-helical bundle structure more efficiently, underlying the mechanism of the enhanced fusion capacity. Also, importantly, the design of membrane fusion inhibitors with high potencies against both SARS-CoV-2 and SARS-CoV has provided potential arsenals to combat the pandemic and tools to exploit the fusion mechanism.

KEYWORDS SARS-CoV-2, fusion inhibitor, lipopeptide, membrane fusion

\footnotetext{
n late December of 2019, a new infectious respiratory disease emerged in Wuhan, China. The pathogen was soon identified to be a novel coronavirus (CoV) (1-3), which was initially termed 2019-nCoV by the World Health Organization (WHO), and the disease was named 2019 coronavirus disease (COVID-19). Because 2019-nCoV shares a high degree of sequence identity to the severe acute respiratory syndrome CoV (SARS-CoV) that emerged previously and uses the same cell receptor, angiotensin-
}

Citation Zhu Y, Yu D, Yan H, Chong H, He Y. 2020. Design of potent membrane fusion inhibitors against SARS-CoV-2, an emerging coronavirus with high fusogenic activity. J Virol 94:e00635-20. https://doi.org/10.1128/JVI .00635-20.

Editor Julie K. Pfeiffer, University of Texas Southwestern Medical Center

Copyright $\odot 2020$ American Society for Microbiology. All Rights Reserved.

Address correspondence to Yuxian He, yhe@ipb.pumc.edu.cn.

Received 7 April 2020

Accepted 4 May 2020

Accepted manuscript posted online 6 May 2020

Published 1 July 2020 
A

HRl sequence

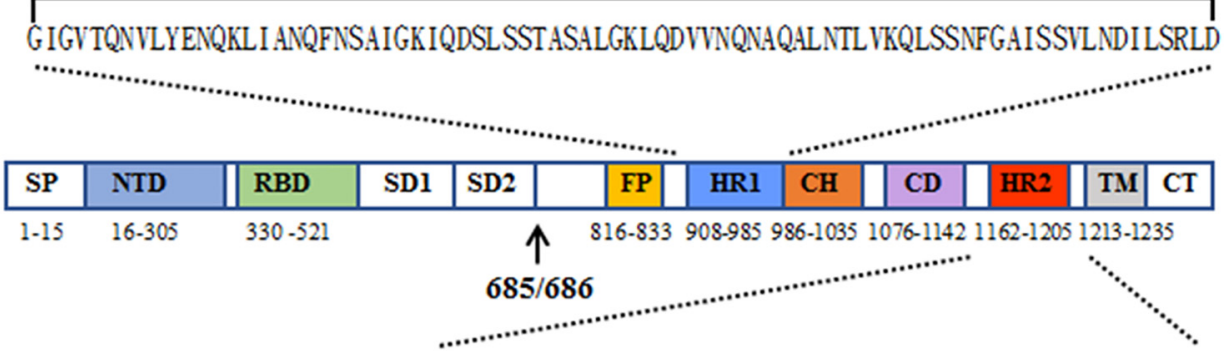

PDVDLGD ISG INASWVNIQKEI DRLNEVAKNLNESLIDLQELGKYEQYIK

B
SARS-CoV-2 HR2-derived peptides
IPB01 ISGINASVVNIQKE IDRLNEVAKNLNESLIDLQEL
IPB02 ISGINASVVNIQKE IDRLNEVAKNLNESLIDLQELK ( $\mathrm{ChOl}$ )
IPB03 INASVVNIQKEIDRLNEVAKNLNESLIDLQELGK (Chol)
IPB04
IPB05
IPB06
IPB07
IPB08
IPB09
SVVNIQKE IDRLNEVAKNLNESLIDLQELGK (ChOl)
IQKE IDRLNEVAKNLNESLIDLQELGK (Chol)
IDRLNEVAKNLNESLIDLQELGK (ChOl)
IQKE IDRLNEVAKNLNESLIDLQELGKYEQYIK (ChOl)
ISGINASVVNIQKEIDRLNEVAKNLNESLIK (ChOl)
SVVNIQKEIDRLNEVAKNLNESLIK (Chol)

FIG 1 Schematic diagram of SARS-CoV-2 S protein and its peptide derivatives. (A) Functional domains of the $S$ protein. SP, signal peptide; NTD, N-terminal domain; RBD, receptor-binding domain; SD, subdomain; FP, fusion peptide; HR1, heptad repeat 1; $C H$, central helix; $C D$, connector domain; HR2, heptad repeat 2; TM, transmembrane domain; CT, cytoplasmic tail. The S1/S2 cleavage site (685/686) is marked. The HR1 and HR2 sequences and membrane-proximal external sequence (MPES) are listed. (B) HR2-derived fusion inhibitor peptides. chol, cholesterol.

converting enzyme 2 (ACE2), for infection $(2,4)$, it was renamed SARS-CoV-2 by the Coronaviridae Study Group (CSG) of the International Committee on Taxonomy of Viruses (ICTV). As of 7 April 2020, a total of 1,214,466 confirmed COVID-19 cases, including 67,767 deaths, have been reported from 211 countries or regions (www.who int/emergencies/diseases/novel-coronavirus-2019). The pandemic has posed serious threats to global public health and economic and social stabilities, calling for the urgent development of vaccines and antiviral drugs.

CoVs, a large group of enveloped viruses with a single positive-stranded RNA genome, are genetically classified into four genera: Alphacoronavirus, Betacoronavirus, Gammacoronavirus, and Deltacoronavirus $(5,6)$. The six previously known CoVs that cause human disease include two alphacoronaviruses (human CoV NL63 [HCoV-NL63] and HCoV-229E) and four betacoronaviruses (HCoV-OC43, HCoV-HKU1, SARS-CoV, and Middle East respiratory syndrome CoV [MERS-CoV]). SARS-CoV-2 belongs to the Betacoronavirus genus and represents the seventh human CoV. Like other CoVs, SARS-CoV-2 uses a glycosylated, homotrimeric class I fusion spike (S) protein to gain entry into host cells (7-9). The S protein comprises the S1 and S2 subunits and exists in a metastable prefusion conformation. The $\mathrm{S} 1$ subunit, which contains a receptor-binding domain (RBD) capable of functional folding independently, is responsible for virus binding to the cell surface receptor. A recent study suggested that the ACE2-binding affinity of the RBD of SARS-CoV-2 is up to 20 -fold higher than that of SARS-CoV, which may contribute to its significantly increased infectivity and transmissibility (7). Receptor binding is deemed to trigger large conformational changes in the $S$ complex, which destabilize the prefusion trimer, resulting in shedding of the $\mathrm{S} 1$ subunit, and activate the fusogenic activity of the S2 subunit (10-12). As illustrated in Fig. 1, the sequence structure of S2 contains an N-terminal fusion peptide (FP), heptad repeat 1 (HR1), heptad repeat 2 (HR2), a transmembrane region (TM), and the cytoplasmic tail (CT). During the fusion 

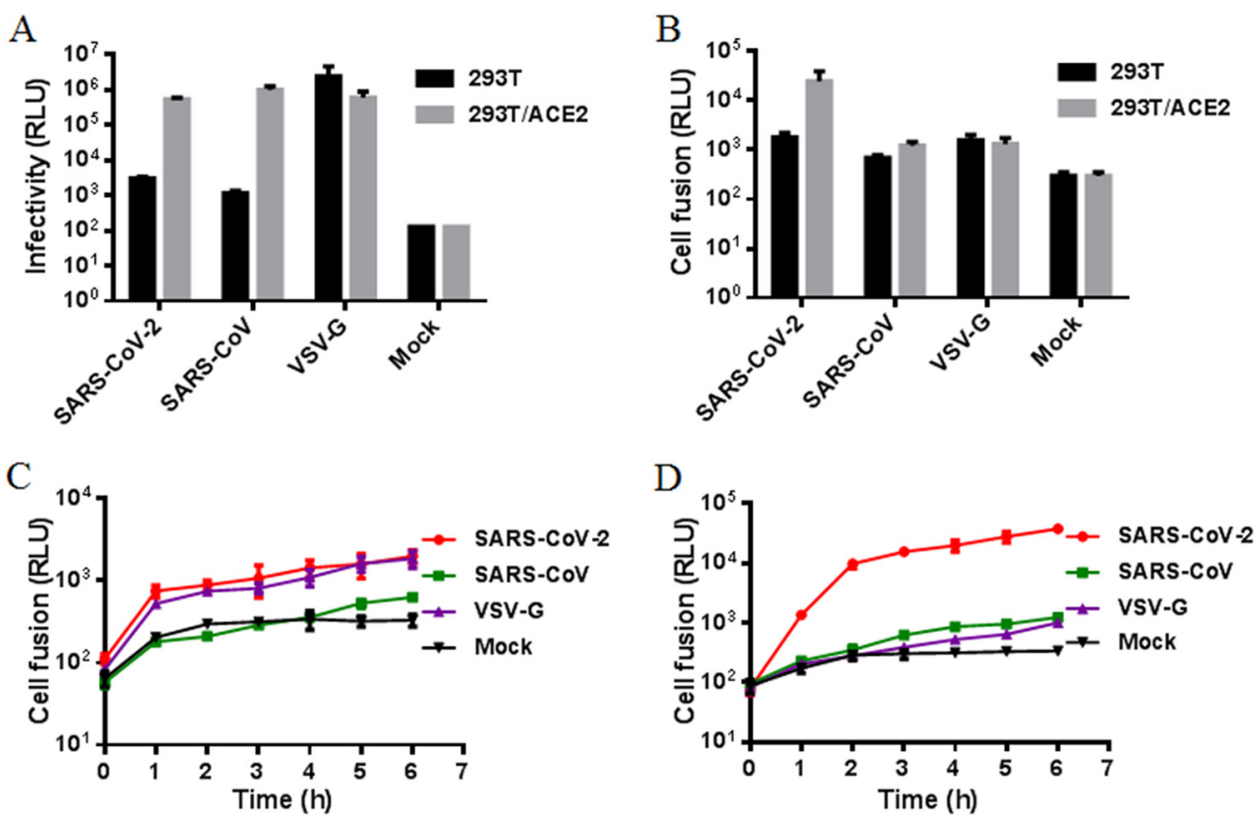

FIG 2 Functional characterization of the SARS-CoV-2 and SARS-CoV S proteins. (A) The infectivity of the SARS-CoV-2 and SARS-CoV pseudoviruses in 293T cells or 293T/ACE2 cells was determined by a single-cycle infection assay. (B) The fusogenic activity of the SARS-CoV-2 and SARS-CoV S proteins with 293T cells or 293T/ACE2 cells as a target was determined by a DSP-based cell fusion assay. (C and D) The fusion activities of S proteins in 293T cells (C) and 293T/ACE2 cells (D) were determined at different time points. The experiments were repeated three times, and the data are expressed as the means \pm standard deviations.

process, the FP is exposed and inserts into the target cell membrane, leading S2 in a prehairpin intermediate that bridges the viral and cell membranes; then, three HR1 segments self-assemble a trimeric coiled-coil and three HR2 segments fold into the grooves on the surface of the HR1 inner core, thereby resulting in a six-helical bundle (6-HB) structure that drives the two membranes in close apposition for fusion.

Peptides derived from the HR1 and HR2 sequences of the class I viral fusion proteins have been demonstrated to possess antiviral activity through binding to the prehairpin intermediate, thus blocking the formation of the viral 6-HB core (13). These peptides have also been found to have activity against emerging CoVs, including SARS-CoV and MERS-CoV $(11,14-16)$. In response to the outbreak of SARS-CoV, a group of HR2-based peptides that could effectively inhibit viral infection was developed (11, 16-19). Recently, a pan-CoV fusion inhibitor, designated EK1, was created and showed inhibitory activities against diverse HCoVs, including SARS-CoV, MERS-CoV, HCoV-229E, HCoVNL63, and HCoV-OC43 (20). However, the previously reported fusion inhibitor peptides often display low antiviral activities with $50 \%$ inhibitory concentrations $\left(\mathrm{IC}_{50}\right)$ in micromolar ranges. In the past decade, we have dedicated our efforts to develop viral fusion inhibitors with improved pharmaceutical profiles, generating a group of lipopeptides with extremely potent antiviral activity (21-26). To fight the COVID-19 pandemic, here we applied our expertise to develop fusion inhibitors against SARS-CoV-2 infection. We found that, different from the $S$ protein of SARS-CoV, the S protein of SARS-CoV-2 has a high cell fusion activity; then, we designed and characterized several lipopeptidebased fusion inhibitors with highly potent activities in inhibiting both SARS-CoV-2 and SARS-CoV.

\section{RESULTS}

SARS-CoV-2 uses ACE2 as a cell receptor, and its S protein displays high fusion activity. Early in the study, we wanted to experimentally verify whether SARS-CoV-2 uses human ACE2 as a receptor for cell entry; thus, we generated pseudotyped lentiviral particles of its $S$ protein. The SARS-CoV and vesicular stomatitis virus $G$ glycoprotein (VSV-G) pseudoviruses were also prepared for comparison. As shown in Fig. 2A, all three 
pseudoviruses efficiently infected 293T cells that stably overexpressed ACE2 (293T/ ACE2 cells); however, the transduction of SARS-CoV-2 and SARS-CoV dramatically decreased in 239T cells which expressed a low level of endogenous ACE2. As a virus control, VSV-G pseudovirus entered 239T cells even more efficiently than it entered 293T/ACE2 cells.

We further compared the fusion activity of viral S protein in 293T and 293T/ACE2 cells by applying a dual-split-protein (DSP)-based cell-cell fusion assay. As shown in Fig. $2 \mathrm{~B}$, the $\mathrm{S}$ proteins of both SARS-CoV-2 and SARS-CoV displayed weak fusion activity in 293T cells, but they showed significantly increased capacities to mediate cell fusion with 293T/ACE2 cells. These results demonstrate that the overexpression of ACE2 can promote the cell entry of both the SARS-CoV-2 and SARS-CoV pseudoviruses as well as $S$ protein-mediated cell-cell fusion activity, verifying the functionality of ACE2 for SARS-CoV-2.

In both the 239T and 293T/ACE2 target cells, we observed that the S protein of SARS-CoV-2 had fusion activity significantly increased over that of the $\mathrm{S}$ protein of SARS-CoV. Therefore, we further compared the fusion activities of the viral S proteins at different time points. As shown in Fig. 2 C and D, the SARS-CoV S protein exhibited no appreciable fusion activity until the effector cells and target cells were cocultured for 5 or $6 \mathrm{~h}$; in sharp contrast, the SARS-CoV-2 S protein mediated a rapid and robust cell fusion reaction, as indicated by its fusion kinetic curves, especially in 293T/ACE2 cells.

Compared to SARS-CoV, SARS-CoV-2 might possess an enhanced HR1-HR2 interaction. Similar to many class I fusion proteins, the interaction between the HR1 and HR2 domains of the CoV fusion protein S2 critically determines viral membrane fusion activity. SARS-CoV-2 has an HR1 sequence with nine amino acid substitutions compared to the HR1 sequence of SARS-CoV, and eight of these are located within the HR1 core site, whereas the two viruses share fully identical HR2 sequences (Fig. 3A). In order to explore the mechanism underlying the highly active fusion activity of the SARS-CoV-2 S protein, we synthesized two peptides corresponding to the HR1 sequence, and their secondary structures were determined by circular dichroism (CD) spectroscopy. As shown in Fig. 3B, the HR1 peptide derived from SARS-CoV-2, designated SARS2NP, showed a typical $\alpha$-helical conformation with an $\alpha$-helical content of $66 \%$, whereas the HR1 peptide from SARS-CoV, designated SARS1NP, had an $\alpha$-helical content of $41 \%$. The thermal stability of the two peptides was further measured. As shown in Fig. 3C, SARS2NP and SARS1NP exhibited melting temperature $\left(T_{m}\right)$ values of 48 and $40^{\circ} \mathrm{C}$, respectively. Furthermore, we synthesized a peptide containing the HR2 sequence, termed IPB01, and its interactions with the two HR1 peptides were analyzed by CD spectroscopy. As shown in Fig. 3D and E, both SARS2NP and SARS1NP interacted with IPB01 to form complexes with typical $\alpha$-helical structures, having $T_{m}$ values of 75 and $68^{\circ} \mathrm{C}$, respectively. In comparison, the complex formed between the SARS2NP and IPB01 peptides was much more stable than the complex formed between the SARS1NP and IPB01 peptides. Taken together, these results suggest that SARS-CoV-2 may have evolved an increased interaction between the HR1 and HR2 domains in the S2 fusion protein compared to that in SARS-CoV, thus critically determining its high fusogenic activity.

The cholesterylated peptide exhibits greatly increased $\alpha$-helical stability and target-binding affinity compared to noncholesterylated peptide. Emerging studies have demonstrated that lipid conjugation is a viable strategy to design peptide-based viral fusion inhibitors with enhanced antiviral activity and in vivo stability (21-26). The resulting lipopeptides are considered to interact preferentially with the viral and cell membranes, thus raising the local concentration of the inhibitors at the site where viral fusion occurs. According to our previous experiences, here we modified the HR2 peptide IBP01 by adding a cholesterol group to its $C$ terminus, resulting in a lipopeptide termed IPB02, as illustrated in Fig. 1B. We first applied CD spectroscopy to determine the structural properties of the inhibitors in the absence or the presence of a target mimic HR1 peptide. As shown in Fig. 4A and B, unconjugated IPB01 alone was largely in a random structure and its $T_{m}$ value could not be defined. In contrast, the lipopeptide 
A

NP peptide

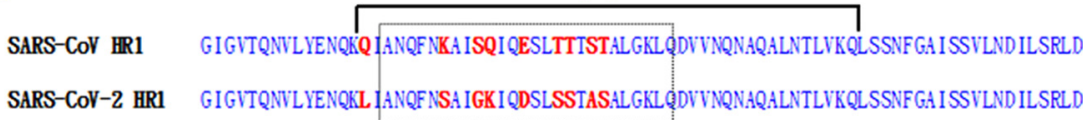

SARS-COV HR2 PDVDLGDISGINASWWNIQKE IDRLNEVAKNLNESLIDLQELGKYEQY IK

SARS-COV-2 HR2 PDVDLGDISGINASWWNIQKE IDRLNEVAKNLNESLIDLQELGGKYQY IK

IPB01 peptide

$\mathrm{B}$

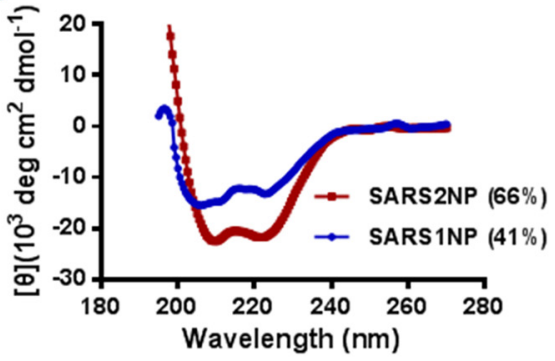

$\mathrm{D}$

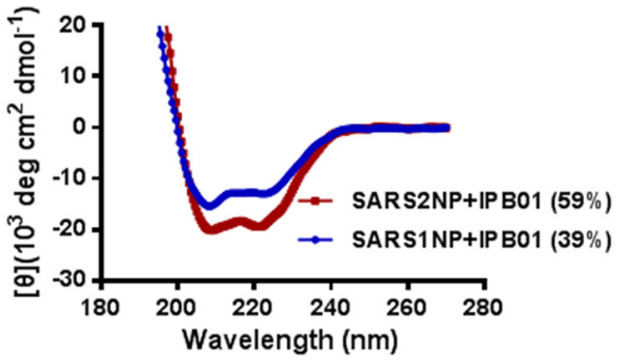

$\mathrm{C}$

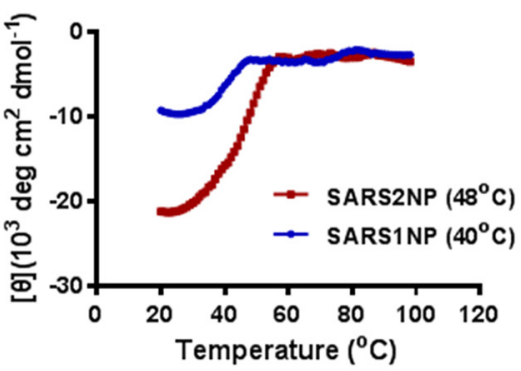

E

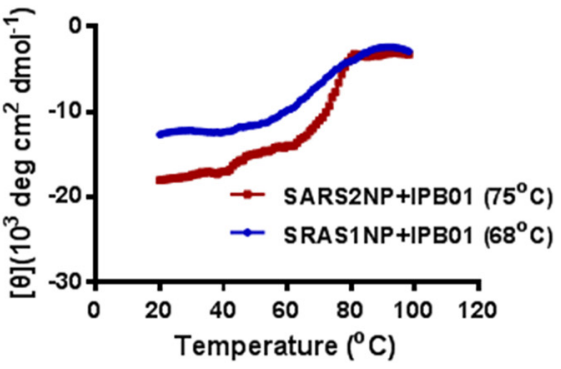

FIG 3 Interactions between the HR1 and HR2 peptides derived from the S2 proteins of SARS-CoV-2 and SARS-CoV. (A) Sequence comparison of the HR1 and HR2 domains in SARS-CoV-2 and SARS-CoV. The sequences in the dotted boxes represent the core sites that mediate the helical interaction between the HR1 and HR2 domains. (B to E) The $\alpha$-helicity and thermostability of the HR1 peptides alone (B and C) or in complexes with an HR2 peptide (D and E) were determined by CD spectroscopy, in which the peptides or peptide mixtures were dissolved in PBS, with the final concentration of each peptide being $10 \mu \mathrm{M}$. The experiments were performed two times, and representative data are shown.

IPB02 displayed markedly increased helix contents with a $T_{m}$ of $65^{\circ} \mathrm{C}$. Next, we assessed the helical binding stability of the inhibitors with the two target mimic peptides, SARS2NP and SARS1NP. As shown in Fig. 4C to F, the lipopeptide-based complexes had sharply increased thermostabilities compared to the complexes formed by the template peptides. Specifically, the IPB02 and SARS2NP complex showed a $T_{m}$ of $89^{\circ} \mathrm{C}$, which was $14^{\circ} \mathrm{C}$ higher than the $T_{m}$ of the IPB01 and SARS2NP complex $\left(75^{\circ} \mathrm{C}\right)$; the IPB02 and SARS1NP complex also had a $T_{m}$ of $89^{\circ} \mathrm{C}$, indicating a $21^{\circ} \mathrm{C}$ increase relative to that of the IPBO-based complex $\left(68^{\circ} \mathrm{C}\right)$. Here the $C D$ results demonstrated that the cholesterol-conjugated peptide IPB02 possesses significantly increased $\alpha$-helical thermostability and target-binding affinity.

We also visualized the formed complexes by a native polyacrylamide gel electrophoresis (N-PAGE) method. As shown in Fig. 5, the positively charged SARS2NP and SARS1NP may have migrated up and off the gel and, thus, no bands appeared, whereas IPB01 and IPB02 showed specific bands because they carried net negative charges. When an HR1 peptide and an inhibitor were mixed, new bands corresponding to the binding complexes emerged at the upper positions of the gel, which verified the interactions between them.

IPBO2 is a highly potent fusion inhibitor of SARS-CoV-2 and SARS-CoV. We next sought to determine the antiviral functions of the IPB01 and IPB02 peptides. First, their inhibitory activities on $\mathrm{S}$ protein-mediated cell-cell fusion were examined by the 

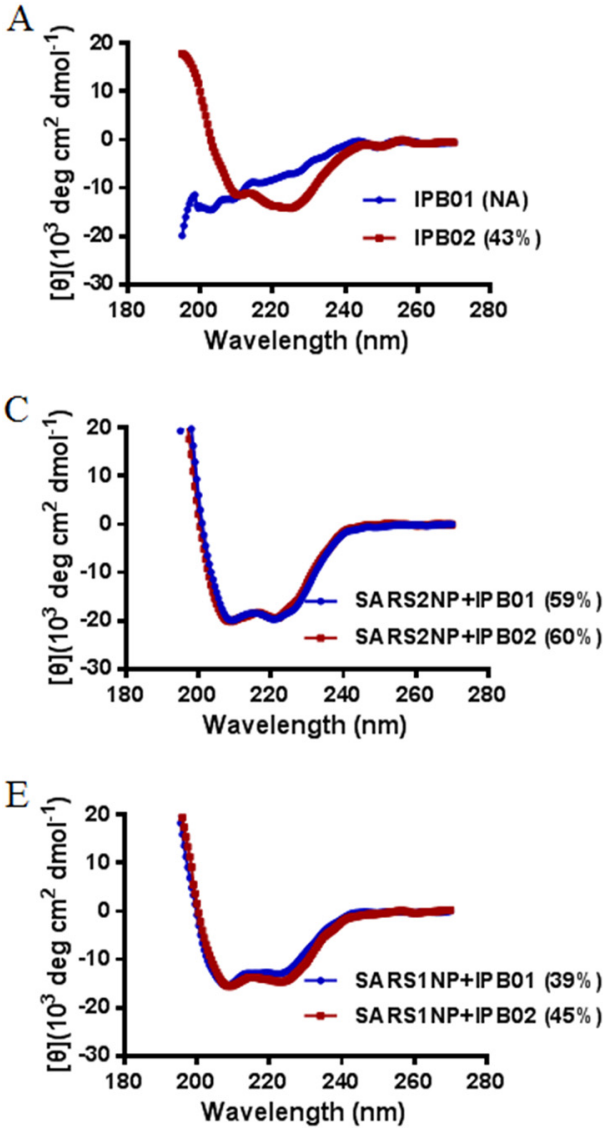
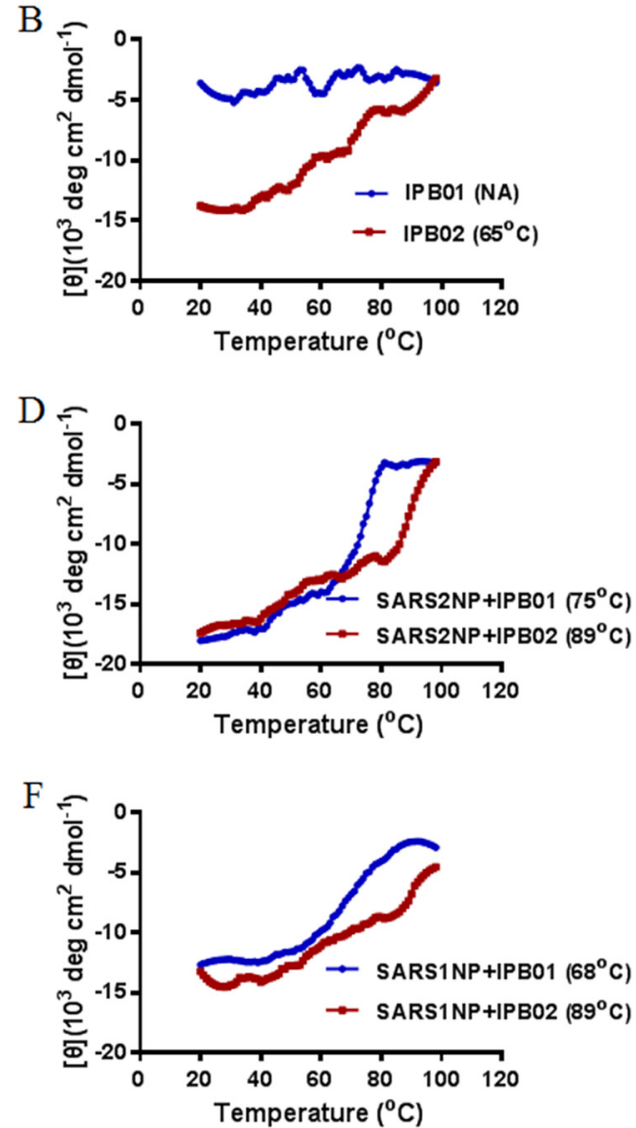

FIG 4 Secondary structure and binding stability of fusion inhibitor peptides determined by CD spectroscopy. The $\alpha$-helicity and thermostability of peptide inhibitors alone (A and B) or in complexes with the SARS-CoV-2 HR1 peptide ( $C$ and $D)$ or the SARS-CoV HR1 peptide ( $E$ and $F$ ) were detected, with the final concentration of each peptide being $10 \mu \mathrm{M}$. The experiments were performed two times, and representative data are shown.

DSP-based cell fusion assay, as described above. As shown in Fig. $6 \mathrm{~A}$ and Table 1, both IPB01 and IPB02 potently inhibited the cell fusion mediated by the $\mathrm{S}$ protein of SARS-CoV-2, with mean $\mathrm{IC}_{50}$ values of 0.022 and $0.025 \mu \mathrm{M}$, respectively. Then, we conducted the single-cycle infection assay to measure the inhibitory activities of the peptides on pseudoviruses. Surprisingly, the unconjugated peptide IPB01 showed very weak or marginal activities in inhibiting the SARS-CoV-2 (Fig. 6B) and SARS-CoV (Fig. 6C)

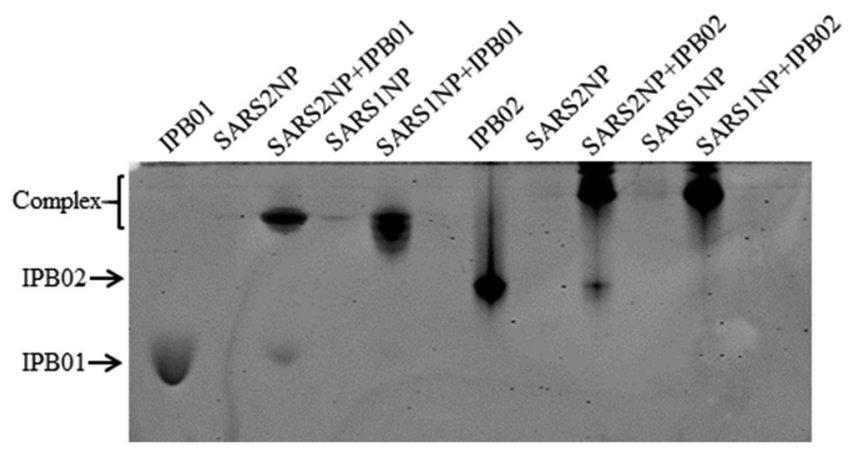

FIG 5 Visualization of the interactions between HR1 peptides and inhibitors by N-PAGE analysis. Each of the peptides was used at a final concentration of $40 \mu \mathrm{M}$. The positively charged peptides SARS2NP and SARS1NP migrated up and off the gel; thus, no bands appeared. IPB01 or IPB02 alone and their complexes with SARS2NP or SARS1NP displayed specific bands because of their net negative charges. The experiments were repeated two times, and representative data are shown. 

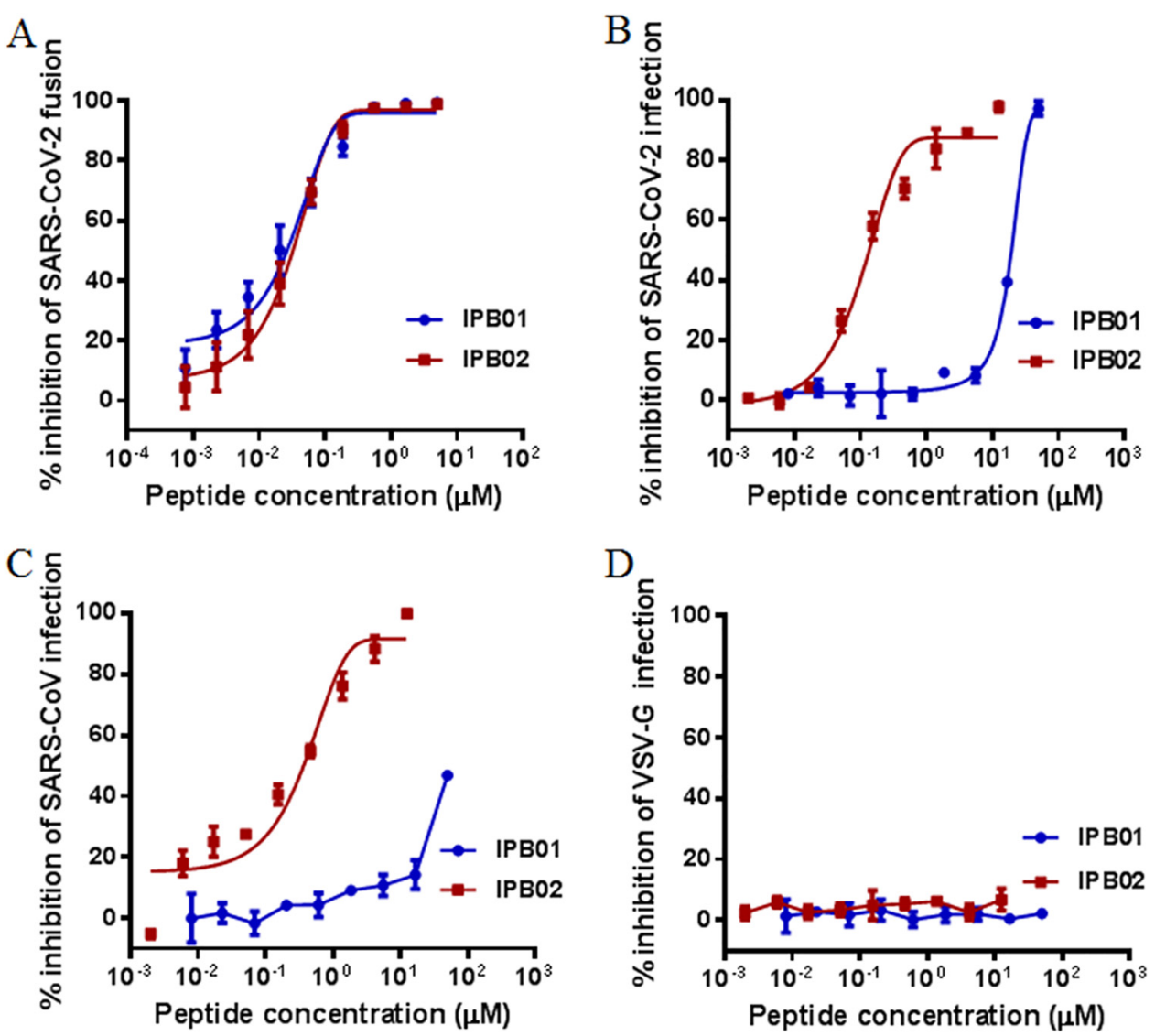

FIG 6 Inhibitory activity of IPB01 and IPB02 against SARS-CoV-2 and SARS-CoV. (A) Inhibition of the SARS-CoV-2 S protein-mediated cell-cell fusion by the inhibitors, determined by a DSP-based cell fusion assay. (B to D) The activity of IPB01 and IPB02 in inhibiting SARS-CoV-2 (B), SARS-CoV (C), and control pseudovirus VSV-G (D) was determined by a single-cycle infection assay. The experiments were repeated three times, and the data are expressed as the means \pm standard deviations.

pseudoviruses; however, the lipopeptide IPB02 inhibited the two pseudoviruses with $I_{50}$ s of 0.08 and $0.251 \mu \mathrm{M}$, respectively (Table 1). As expected, IPB01 and IPB02 had no inhibitory activity against a control pseudotype (VSV-G), indicating their antiviral specificities. Therefore, we conclude that IPB02 is a highly potent fusion inhibitor of SARS-CoV-2 and SARS-CoV.

Structural and functional characterization of lipopeptide inhibitors. In light of the high binding and inhibitory activities of IPB02, we next focused on characterizing its structure-activity relationship (SAR). To this end, a panel of new lipopeptides was

TABLE 1 Structural and functional characterization of the activity of lipopeptide fusion inhibitors against SARS-CoV-2 and SARS-CoV ${ }^{a}$

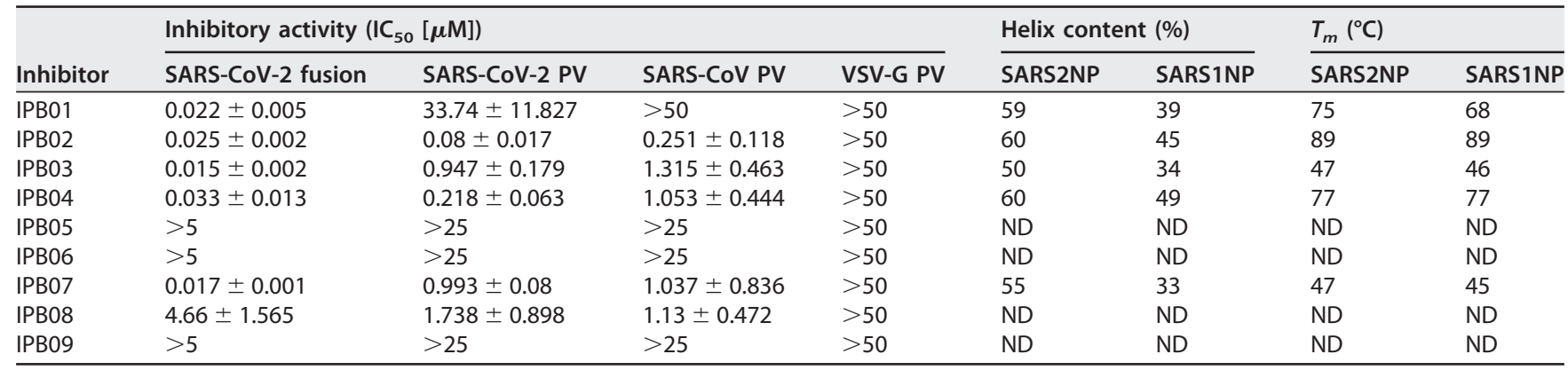

${ }^{a}$ The antiviral assays were repeated three times, and data are expressed as the means \pm standard deviations. PV, pseudovirus. The CD experiment was repeated two times, and representative data are shown. ND, not done, owing to the solubility problem of the peptides in PBS. 
generated by sequence truncation or extension, and their antiviral capacities were examined. As shown in Table 1, IPB03 and IPB04, which had an N-terminal amino acid truncation, still maintained a very high potency in inhibiting the cell fusion activity of the SARS-CoV-2 S protein, but they exhibited an obviously reduced activity to block the cell entry activity of both the SARS-CoV-2 and SARS-CoV pseudoviruses. A further $\mathrm{N}$-terminal truncation, as indicated by IPB05 and IPB06, resulted in inhibitors inactive at a high concentration. By adding 6 amino acids of the membrane-proximal external sequence (MPES) to the $C$ terminus of IPB05, the resulting peptide, IPB07, regained antiviral activity, demonstrating the importance of MPES in the design of such CoV fusion inhibitors. A different construct, IPB08, was a C-terminally truncated inhibitor with IPB02 as the template, but its antiviral function was markedly impaired, underscoring the roles of C-terminal residues in IPB02. On the basis of the results presented above, it was expected that IPB09 with two terminal truncations was antivirally inactive. Indeed, the CD data suggested that both the $\mathrm{N}$ - and C-terminal sequences contributed critically to the binding of the inhibitors (Table 1). Comparison of IPB03 and IPB04 revealed that three amino acids (Ile-Asn-Ala) in the $\mathrm{N}$ terminus of IPB03 reversely impaired inhibitor binding.

\section{DISCUSSION}

In 2002, SARS-CoV suddenly emerged in Guangzhou, China, and its subsequent global spread was associated with 8,096 cases and 774 deaths. To fight against SARS-CoV, we took immediate actions with multiple research projects and achieved significant findings. First, we identified several viral antigens suitable for the development of diagnostic tools (27-29); second, we proposed for the first time that the S protein receptor-binding domain (RBD) can serve as an ideal subunit vaccine for emerging CoVs (30-41); third, we also reported the first peptide-based SARS-CoV fusion inhibitor with potential therapeutic and preventive efficacies (11).

To fight against the current pandemic of COVID-19, caused by SARS-CoV-2, we sprang into action to develop effective therapeutics and prophylactics. In this study, we focused on developing viral fusion inhibitor peptides with potent and broad antiviral activity. First, our experiments verified that, like SARS-CoV, SARS-CoV-2 also uses human ACE2 as a receptor for cell entry and infection; however, the S protein of SARS-CoV-2 has much higher activity to mediate cell-cell fusion. By analyzing the secondary structure and thermostability by CD spectroscopy, we found that the HR1 peptide derived from the S2 fusion protein of SARS-CoV-2 displays much higher $\alpha$-helicity and thermostability than the HR1 peptide derived from the S2 fusion protein of SARS-CoV. Consistently, both the $\alpha$-helical contents and melting temperature of the SARS-CoV-2 HR1 peptide complexed with an HR2-derived peptide are higher than those of the SARS-CoV HR1 peptide-based complex, suggesting a stronger interaction between the HR1 and HR2 sites for SARS-CoV-2 than for SARS-CoV. According to our experiences in the design of a lipopeptide fusion inhibitor against HIV, we modified the HR2 sequencederived peptide IPB01 with a cholesterol group, resulting in the lipopeptide IPB02 with highly potent activities in inhibiting SARS-CoV-2 and SARS-CoV pseudoviruses as well as $S$ protein-mediated cell-cell fusion activity. Moreover, the structure-activity relationships (SAR) of the HR2 sequence-based fusion inhibitors were characterized by applying a panel of truncated lipopeptides, which certified the roles of both the $\mathrm{N}$-and C-terminal amino acid sequences in the design of a potent inhibitor against emerging CoVs. Combined, these data provide important information for understanding the fusion mechanism of emerging CoVs and for the development of antivirals that target the membrane fusion step.

The cell entry of CoVs depends on the binding of the viral S proteins to cellular receptors and on S protein priming by host cell proteases (42-45). Previous studies demonstrated that SARS-CoV enters the targeted cells mainly via an endosome membrane fusion pathway, where its $S$ protein is cleaved by endosomal cysteine proteases cathepsin B and L (CatB/L) and activated (46). However, SARS-CoV also employs the plasma membrane-associated serine protease TMPRSS2 for $\mathrm{S}$ protein priming, and 
especially, TMPRSS2 but not CatB/L is essential for viral entry into primary target cells and for viral spread in the infected host $(44,47-49)$. It was also found that introducing a furin recognition site between the $\mathrm{S} 1$ and $\mathrm{S} 2$ subunits significantly increased the ability of the SARS-CoV S protein to mediate cellular membrane surface infection (50). Differently from SARS-CoV, SARS-CoV-2 induces typical syncytium formation in infected cells, suggesting that it mainly utilizes a plasma membrane fusion pathway for cell entry (51). Sequence analyses revealed that SARS-CoV-2 harbors the S1/S2 cleavage site in its $S$ protein, although its roles in $S$ protein-mediated membrane fusion and the viral life cycle need to be characterized $(4,8)$. One can speculate that furin-mediated precleavage at the S1/S2 site in infected cells may promote subsequent TMPRSS2-dependent cell entry, which is the case for MERS-CoV $(52,53)$. A recent study found that SARSCoV-2 employs TMPRSS2 for S protein priming and that a TMPRSS2 inhibitor approved for clinical use can block entry (4). For most viruses, the plasma membrane fusion pathway is more efficient than the endosome membrane fusion pathway because the latter is prone to activating host antiviral immunity $(54,55)$. In this study, we have not only verified that ACE2 is a cell receptor but also demonstrated that the SARS-CoV-2 S protein evolves a significantly increased fusogenic activity relative to the $S$ protein of SARS-CoV. Although our studies have also shown that the HR1 mutations in the S2 protein can greatly enhance the HR1-HR2 interaction and may thus be a crucial factor to determine the fusion activity of the SARS-CoV-2 S protein, other players in the fusion pathways may contribute in coordination with that. We also observed that the HR2derived inhibitors were more effective in inhibiting the $\mathrm{S}$ protein-mediated cell fusion of SARS-CoV-2 than in inhibiting that of pseudoviruses, implying that SARS-CoV-2 may also adopt the endosome entry pathway. Very recently, Xia and coworkers also found similar phenomena with different experimental systems $(51,56)$. Indeed, it was found that cathepsin $L$ is required for the cell entry of SARS-CoV-2 and that teicoplanin, $a$ glycopeptide antibiotic, can specifically inhibit the entry $(57,58)$.

Repurposing of existing drugs represents a viable drug discovery strategy because their safety profiles, side effects, posologies, and drug interactions are known, and this knowledge may shorten the time to development as a therapeutic and reduce the cost of development compared to those required for de novo drug discovery. In the emergency of the COVID-19 pandemic, a group of nonspecific antiviral drugs, including interferon (IFN), lopinavir-ritonavir, chloroquine, remdesivir (GS-5734), and favipiravir (T-705), were quickly screened for anti-SARS-CoV-2 activity, and they have been used to treat infected patients $(59,60)$. Very recently, a clinical study suggested that the combination of hydroxychloroquine and azithromycin may provide synergistic effects when used to treat COVID-19 patients (61). Nonetheless, the development of specific drugs for the treatment of infections caused by emerging coronaviruses, including SARS-CoV-2 and SARS-CoV, is strongly required. As mentioned above, the entry of SARS-CoV-2 into lung cells may mainly depend on $\mathrm{S}$ protein activation by plasma TMPRSS2, and thus, a membrane fusion inhibitor might not need to be taken up into lung cells to unfold its antiviral activity, which may result in more potent inhibitory activity. We believe that the newly developed lipopeptide IPB02 represents an ideal candidate for optimization and development. In our future studies, we would like to confirm the antiviral activity of IPBO2 and its derivatives with authentic SARS-CoV-2 infection and evaluate their in vivo therapeutic efficacy in animal models. The IPB02based peptides can be more easily produced on a large scale and are more costeffective than neutralizing antibodies and other large protein-based inhibitors. Furthermore, we think that a peptide inhibitor can be applied topically for the treatment and prevention of emerging CoVs.

\section{MATERIALS AND METHODS}

Peptide synthesis. Peptides were synthesized on rink amide 4-methylbenzhydrylamine (MBHA) resin using a standard solid-phase 9-flurorenylmethoxycarbonyl (FMOC) protocol as described previously (21). Lipopeptides were produced by conjugating cholesterol succinate monoester to the C-terminal lysine residue. All peptides were $\mathrm{N}$-terminally acetylated and C-terminally amidated, and they were purified by 
reverse-phase high-performance liquid chromatography (HPLC) to more than 95\% homogeneity and characterized by mass spectrometry.

Single-cycle infection assay. The infectivity of SARS-CoV-2, SARS-CoV, and vesicular stomatitis virus (VSV) for 293T cells or 293T cells stably expressing human ACE2 (293T/ACE2) was determined by a single-cycle infection assay as described previously (62). To produce pseudoviruses, 293T cells were cotransfected with a backbone plasmid (pNL4-3.luc.RE) that encodes an Env-defective, luciferase reporter-expressing HIV-1 genome and a plasmid expressing the S protein of SARS-CoV-2 or SARS-CoV or the G protein of VSV. Cell culture supernatants containing the released virions were harvested at 48 h posttransfection, filtrated, and stored at $-80^{\circ} \mathrm{C}$. To measure the inhibitory activity of peptide inhibitors, pseudoviruses were mixed with an equal volume of a serially 3-fold-diluted peptide and incubated at $37^{\circ} \mathrm{C}$ for $30 \mathrm{~min}$. The mixture was then added to $293 \mathrm{~T} / \mathrm{ACE} 2$ cells at a density of $10^{4} \mathrm{cells} / 100 \mu \mathrm{l}$ per plate well. After they were cultured at $37^{\circ} \mathrm{C}$ for $48 \mathrm{~h}$, the cells were harvested and lysed in reporter lysis buffer, and luciferase activity was measured using luciferase assay reagents and a luminescence counter (Promega, Madison, WI, USA). The 50\% inhibitory concentration $\left(\mathrm{IC}_{50}\right.$ ) was calculated as the final cell culture concentration of an inhibitor that caused a $50 \%$ reduction in relative luminescence units (RLU) compared to the level of the virus control subtracted from that of the cell control.

Cell-cell fusion assay. A dual-split-protein (DSP)-based cell-cell fusion assay was used to detect SARS-CoV-2 or SARS-CoV S protein-mediated cell-cell fusion activity and the inhibitory activity of the peptides, as described previously (62). Briefly, a total of $1.5 \times 10^{4} 293$ T cells (effector cells) were seeded in a 96-well plate and $1.5 \times 10^{5} / \mathrm{ml} 293$ T or 293T/ACE2 cells (target cells) were seeded in a 10-cm culture dish, and then the cells were incubated at $37^{\circ} \mathrm{C}$. On the next day, the effector cells were cotransfected with an $\mathrm{S}$ protein-expressing and a $\mathrm{DSP}_{1-7}$ plasmid, the target cells were transfected with a DSP $_{8-11}$ plasmid, and then the cells were incubated at $37^{\circ} \mathrm{C}$. After $24 \mathrm{~h}$, a serially 3 -fold-diluted peptide was added to the effector cells and the cells were incubated for $1 \mathrm{~h}$; the target cells were resuspended at $3 \times 10^{5} / \mathrm{ml}$ in prewarmed culture medium that contained EnduRen live cell substrate (Promega) at a final concentration of $17 \mathrm{ng} / \mathrm{ml}$ and incubated for $30 \mathrm{~min}$. Then, $3 \times 10^{4}$ target cells were transferred to the effector cells and the mixture of cells was spun down to maximize cell-cell contact. After incubation for $2 \mathrm{~h}$, luciferase activity was measured and $I C_{50}$ values were calculated as described above.

CD spectroscopy. The secondary structure and thermal stability of peptides or peptide complexes were determined by circular dichroism (CD) spectroscopy as described previously (62). Briefly, a peptide was dissolved in phosphate-buffered saline (PBS; $\mathrm{pH}$ 7.2) at a final concentration of $10 \mu \mathrm{M}$ and incubated at $37^{\circ} \mathrm{C}$ for $30 \mathrm{~min}$. CD spectra were acquired on a Jasco spectropolarimeter (model J-815) using a 1-nm bandwidth with a 1-nm step resolution from 195 to $270 \mathrm{~nm}$ at room temperature. The spectra were corrected by subtracting a solvent blank, and the $\alpha$-helical content was calculated from the CD signal by dividing the mean residue ellipticity $([\theta])$ at $222 \mathrm{~nm}$ by a value of $-33,000$ degrees $\mathrm{cm}^{2} \mathrm{dmol}^{-1}$, corresponding to a $100 \%$ helix. Thermal denaturation was conducted by monitoring the ellipticity change at $222 \mathrm{~nm}$ from 20 to $98^{\circ} \mathrm{C}$ at a rate of $2^{\circ} \mathrm{C} / \mathrm{min}$, and the melting temperature $\left(T_{m}\right)$ was defined as the midpoint of the thermal unfolding transition.

N-PAGE. Native polyacrylamide gel electrophoresis (N-PAGE) was performed to determine the interaction between a SARS-CoV2 or a SARS-CoV S protein HR1-derived peptide and an HR2-derived peptide as described previously (63). Briefly, an HR1 peptide was mixed with an HR2 peptide at a final concentration of $40 \mu \mathrm{M}$, and the mixture was incubated at $37^{\circ} \mathrm{C}$ for $30 \mathrm{~min}$. Tris-glycine native sample buffer was added to the mixture at a ratio of 1:1, and then the mixture was loaded onto a 10- by $1.0-\mathrm{mm}$ Tris-glycine gel (20\%) at $25 \mu \mathrm{l} /$ well. Gel electrophoresis was done with a $100-\mathrm{V}$ constant voltage at $4^{\circ} \mathrm{C}$ for $3 \mathrm{~h}$. The gel was then stained with Coomassie blue and imaged with a Bio-Rad imaging system (Bio-Rad, Hercules, CA, USA).

Data availability. All data are fully available without restriction.

\section{ACKNOWLEDGMENTS}

We thank Zene Matsuda at the Institute of Medical Science, University of Tokyo, for providing plasmids and cells for the DSP-based cell-cell fusion assay.

This work was supported by grants from the National Natural Science Foundation of China (grant 81630061) and the CAMS Innovation Fund for Medical Sciences (grant 2017-I2M-1-014).

\section{REFERENCES}

1. Wu F, Zhao S, Yu B, Chen YM, Wang W, Song ZG, Hu Y, Tao ZW, Tian JH, Pei YY, Yuan ML, Zhang YL, Dai FH, Liu Y, Wang QM, Zheng JJ, Xu L, Holmes EC, Zhang YZ. 2020. A new coronavirus associated with human respiratory disease in China. Nature 579:265-269. https://doi.org/10 .1038/s41586-020-2008-3.

2. Zhou $P$, Yang $X L$, Wang XG, Hu B, Zhang L, Zhang W, Si HR, Zhu Y, Li B, Huang $C L$, Chen HD, Chen J, Luo $Y$, Guo $H$, Jiang RD, Liu MQ, Chen $Y$, Shen XR, Wang X, Zheng XS, Zhao K, Chen QJ, Deng F, Liu LL, Yan B, Zhan FX, Wang YY, Xiao GF, Shi ZL. 2020. A pneumonia outbreak associated with a new coronavirus of probable bat origin. Nature 579: 270-273. https://doi.org/10.1038/s41586-020-2012-7.
3. Zhu N, Zhang D, Wang W, Li X, Yang B, Song J, Zhao X, Huang B, Shi W, Lu R, Niu P, Zhan F, Ma X, Wang D, Xu W, Wu G, Gao GF, Tan W, China Novel Coronavirus Investigating and Research Team. 2020. A novel coronavirus from patients with pneumonia in China, 2019. N Engl J Med 382:727-733. https://doi.org/10.1056/NEJMoa2001017.

4. Hoffmann $M$, Kleine-Weber $H$, Schroeder $S$, Krüger $N$, Herrler $T$, Erichsen S, Schiergens TS, Herrler G, Wu N-H, Nitsche A, Müller MA, Drosten C, Pöhlmann S. 2020. SARS-CoV-2 cell entry depends on ACE2 and TMPRSS2 and is blocked by a clinically proven protease inhibitor. Cell 181:271-280. https://doi.org/10.1016/j.cell.2020.02.052.

5. Perlman S, Netland J. 2009. Coronaviruses post-SARS: update on repli- 
cation and pathogenesis. Nat Rev Microbiol 7:439-450. https://doi.org/ 10.1038/nrmicro2147.

6. Li F. 2016. Structure, function, and evolution of coronavirus spike proteins. Annu Rev Virol 3:237-261. https://doi.org/10.1146/annurev-virology-110615 $-042301$.

7. Wrapp D, Wang N, Corbett KS, Goldsmith JA, Hsieh CL, Abiona O, Graham BS, McLellan JS. 2020. Cryo-EM structure of the 2019-nCoV spike in the prefusion conformation. Science 367:1260-1263. https://doi.org/ 10.1126/science.abb2507.

8. Walls AC, Park YJ, Tortorici MA, Wall A, McGuire AT, Veesler D. 2020. Structure, function, and antigenicity of the SARS-CoV-2 spike glycoprotein. Cell 181:281-292.e6. https://doi.org/10.1016/j.cell.2020.02.058.

9. Wan Y, Shang J, Graham R, Baric RS, Li F. 2020. Receptor recognition by the novel coronavirus from Wuhan: an analysis based on decade-long structural studies of SARS coronavirus. J Virol 94:e00127-20. https://doi org/10.1128/JVI.00127-20.

10. Walls AC, Tortorici MA, Snijder J, Xiong X, Bosch BJ, Rey FA, Veesler D. 2017. Tectonic conformational changes of a coronavirus spike glycoprotein promote membrane fusion. Proc Natl Acad Sci U S A 114: 11157-11162. https://doi.org/10.1073/pnas.1708727114.

11. Liu S, Xiao G, Chen Y, He Y, Niu J, Escalante CR, Xiong H, Farmar J, Debnath AK, Tien P, Jiang S. 2004. Interaction between heptad repeat 1 and 2 regions in spike protein of SARS-associated coronavirus: implications for virus fusogenic mechanism and identification of fusion inhibitors. Lancet 363:938-947. https://doi.org/10.1016/S0140-6736(04) 15788-7.

12. Bosch BJ, van der Zee R, de Haan CA, Rottier PJ. 2003. The coronavirus spike protein is a class I virus fusion protein: structural and functional characterization of the fusion core complex. J Virol 77:8801-8811. https://doi.org/10.1128/jvi.77.16.8801-8811.2003.

13. He Y. 2013. Synthesized peptide inhibitors of HIV-1 gp41-dependent membrane fusion. Curr Pharm Des 19:1800-1809. https://doi.org/10 $.2174 / 1381612811319100004$.

14. Lu L, Liu Q, Zhu Y, Chan KH, Qin L, Li Y, Wang Q, Chan JF, Du L, Yu F, Ma C, Ye S, Yuen KY, Zhang R, Jiang S. 2014. Structure-based discovery of Middle East respiratory syndrome coronavirus fusion inhibitor. Nat Commun 5:3067. https://doi.org/10.1038/ncomms4067.

15. Wang C, Xia S, Zhang P, Zhang T, Wang W, Tian Y, Meng G, Jiang S, Liu K. 2018. Discovery of hydrocarbon-stapled short alpha-helical peptides as promising Middle East respiratory syndrome coronavirus (MERS-CoV) fusion inhibitors. J Med Chem 61:2018-2026. https://doi.org/10.1021/ acs.jmedchem.7b01732.

16. Bosch BJ, Martina BE, Van Der Zee R, Lepault J, Haijema BJ, Versluis C, Heck AJ, De Groot R, Osterhaus AD, Rottier PJ. 2004. Severe acute respiratory syndrome coronavirus (SARS-CoV) infection inhibition using spike protein heptad repeat-derived peptides. Proc Natl Acad Sci U S A 101:8455-8460. https://doi.org/10.1073/pnas.0400576101.

17. Ujike M, Nishikawa H, Otaka A, Yamamoto N, Yamamoto N, Matsuoka M, Kodama E, Fujii N, Taguchi F. 2008. Heptad repeat-derived peptides block protease-mediated direct entry from the cell surface of severe acute respiratory syndrome coronavirus but not entry via the endosomal pathway. J Virol 82:588-592. https://doi.org/10.1128/JVI.01697-07.

18. Liu IJ, Kao CL, Hsieh SC, Wey MT, Kan LS, Wang WK. 2009. Identification of a minimal peptide derived from heptad repeat (HR) 2 of spike protein of SARS-CoV and combination of HR1-derived peptides as fusion inhibitors. Antiviral Res 81:82-87. https://doi.org/10.1016/j.antiviral.2008.10 .001 .

19. Aydin H, Al-Khooly D, Lee JE. 2014. Influence of hydrophobic and electrostatic residues on SARS-coronavirus S2 protein stability: insights into mechanisms of general viral fusion and inhibitor design. Protein Sci 23:603-617. https://doi.org/10.1002/pro.2442.

20. Xia S, Yan L, Xu W, Agrawal AS, Algaissi A, Tseng CK, Wang Q, Du L, Tan W, Wilson IA, Jiang S, Yang B, Lu L. 2019. A pan-coronavirus fusion inhibitor targeting the HR1 domain of human coronavirus spike. Sci Adv 5:eaav4580. https://doi.org/10.1126/sciadv.aav4580.

21. Zhu Y, Chong H, Yu D, Guo Y, Zhou Y, He Y. 2019. Design and characterization of cholesterylated peptide HIV-1/2 fusion inhibitors with extremely potent and long-lasting antiviral activity. J Virol 93:e02312-18. https://doi.org/10.1128/JVI.02312-18.

22. Chong H, Xue J, Zhu Y, Cong Z, Chen T, Wei Q, Qin C, He Y. 2019. Monotherapy with a low-dose lipopeptide HIV fusion inhibitor maintains long-term viral suppression in rhesus macaques. PLoS Pathog 15: e1007552. https://doi.org/10.1371/journal.ppat.1007552.

23. Zhu Y, Zhang X, Ding X, Chong H, Cui S, He J, Wang X, He Y. 2018.
Exceptional potency and structural basis of a T1249-derived lipopeptide fusion inhibitor against HIV-1, HIV-2, and simian immunodeficiency virus. J Biol Chem 293:5323-5334. https://doi.org/10.1074/jbc.RA118.001729.

24. Chong H, Zhu Y, Yu D, He Y. 2018. Structural and functional characterization of membrane fusion inhibitors with extremely potent activity against HIV-1, HIV-2, and simian immunodeficiency virus. J Virol 92: e01088-18. https://doi.org/10.1128/JVI.01088-18.

25. Chong H, Xue J, Zhu Y, Cong Z, Chen T, Guo Y, Wei Q, Zhou Y, Qin C, He Y. 2018. Design of novel HIV-1/2 fusion inhibitors with high therapeutic efficacy in rhesus monkey models. J Virol 92:e00775-18. https://doi.org/ 10.1128/JVI.00775-18

26. Chong $H$, Xue J, Xiong $S$, Cong $Z$, Ding $X$, Zhu $Y$, Liu Z, Chen T, Feng $Y$, He L, Guo Y, Wei Q, Zhou Y, Qin C, He Y. 2017. A lipopeptide HIV-1/2 fusion inhibitor with highly potent in vitro, ex vivo, and in vivo antiviral activity. J Virol 91:e00288-17. https://doi.org/10.1128/JVI.00288-17.

27. He $Y$, Zhou $Y$, Siddiqui $P$, Niu J, Jiang S. 2005. Identification of immunodominant epitopes on the membrane protein of the severe acute respiratory syndrome-associated coronavirus. J Clin Microbiol 43:3718-3726. https://doi.org/10.1128/JCM.43.8.3718-3726.2005.

28. He Y, Zhou Y, Wu H, Luo B, Chen J, Li W, Jiang S. 2004. Identification of immunodominant sites on the spike protein of severe acute respiratory syndrome (SARS) coronavirus: implication for developing SARS diagnostics and vaccines. J Immunol 173:4050-4057. https://doi.org/10.4049/ jimmunol.173.6.4050.

29. He Y, Zhou Y, Wu H, Kou Z, Liu S, Jiang S. 2004. Mapping of antigenic sites on the nucleocapsid protein of the severe acute respiratory syndrome coronavirus. J Clin Microbiol 42:5309-5314. https://doi.org/10 .1128/JCM.42.11.5309-5314.2004.

30. Cao Z, Liu L, Du L, Zhang C, Jiang S, Li T, He Y. 2010. Potent and persistent antibody responses against the receptor-binding domain of SARS-CoV spike protein in recovered patients. Virol J 7:299. https://doi .org/10.1186/1743-422X-7-299.

31. He Y, Barker SJ, MacDonald AJ, Yu Y, Cao L, Li J, Parhar R, Heck S, Hartmann S, Golenbock DT, Jiang S, Libri NA, Semper AE, Rosenberg WM, Lustigman S. 2009. Recombinant Ov-ASP-1, a Th1-biased protein adjuvant derived from the helminth Onchocerca volvulus, can directly bind and activate antigen-presenting cells. J Immunol 182:4005-4016. https://doi.org/10.4049/jimmunol.0800531.

32. He Y, Li J, Li W, Lustigman S, Farzan M, Jiang S. 2006. Cross-neutralization of human and palm civet severe acute respiratory syndrome coronaviruses by antibodies targeting the receptor-binding domain of spike protein. J Immunol 176:6085-6092. https://doi.org/10.4049/jimmunol .176 .10 .6085 .

33. He Y, Li J, Jiang S. 2006. A single amino acid substitution (R441A) in the receptor-binding domain of SARS coronavirus spike protein disrupts the antigenic structure and binding activity. Biochem Biophys Res Commun 344:106-113. https://doi.org/10.1016/j.bbrc.2006.03.139.

34. He Y, Li J, Heck S, Lustigman S, Jiang S. 2006. Antigenic and immunogenic characterization of recombinant baculovirus-expressed severe acute respiratory syndrome coronavirus spike protein: implication for vaccine design. J Virol 80:5757-5767. https://doi.org/10.1128/JVI .00083-06.

35. He Y, Li J, Du L, Yan X, Hu G, Zhou Y, Jiang S. 2006. Identification and characterization of novel neutralizing epitopes in the receptor-binding domain of SARS-CoV spike protein: revealing the critical antigenic determinants in inactivated SARS-CoV vaccine. Vaccine 24:5498-5508. https://doi.org/10.1016/j.vaccine.2006.04.054.

36. He Y. 2006. Immunogenicity of SARS-CoV: the receptor-binding domain of $S$ protein is a major target of neutralizing antibodies. Adv Exp Med Biol 581:539-542. https://doi.org/10.1007/978-0-387-33012-9_98.

37. He Y, Zhu Q, Liu S, Zhou Y, Yang B, Li J, Jiang S. 2005. Identification of a critical neutralization determinant of severe acute respiratory syndrome (SARS)-associated coronavirus: importance for designing SARS vaccines. Virology 334:74-82. https://doi.org/10.1016/j.virol.2005.01 .034 .

38. He Y, Lu H, Siddiqui P, Zhou Y, Jiang S. 2005. Receptor-binding domain of severe acute respiratory syndrome coronavirus spike protein contains multiple conformation-dependent epitopes that induce highly potent neutralizing antibodies. J Immunol 174:4908-4915. https://doi.org/10 .4049/jimmunol.174.8.4908.

39. He Y, Jiang S. 2005. Vaccine design for severe acute respiratory syndrome coronavirus. Viral Immunol 18:327-332. https://doi.org/10.1089/ vim.2005.18.327.

40. He $Y$, Zhou $Y$, Siddiqui $P$, Jiang S. 2004. Inactivated SARS-CoV vaccine 
elicits high titers of spike protein-specific antibodies that block receptor binding and virus entry. Biochem Biophys Res Commun 325:445-452. https://doi.org/10.1016/j.bbrc.2004.10.052.

41. He Y, Zhou Y, Liu S, Kou Z, Li W, Farzan M, Jiang S. 2004. Receptorbinding domain of SARS-CoV spike protein induces highly potent neutralizing antibodies: implication for developing subunit vaccine. Biochem Biophys Res Commun 324:773-781. https://doi.org/10.1016/j .bbrc.2004.09.106

42. Li W, Moore MJ, Vasilieva N, Sui J, Wong SK, Berne MA, Somasundaran M, Sullivan JL, Luzuriaga K, Greenough TC, Choe H, Farzan M. 2003. Angiotensin-converting enzyme 2 is a functional receptor for the SARS coronavirus. Nature 426:450-454. https://doi.org/10.1038/nature02145.

43. Li F, Li W, Farzan M, Harrison SC. 2005. Structure of SARS coronavirus spike receptor-binding domain complexed with receptor. Science 309: 1864-1868. https://doi.org/10.1126/science.1116480.

44. Glowacka I, Bertram S, Muller MA, Allen P, Soilleux E, Pfefferle S, Steffen I, Tsegaye TS, He Y, Gnirss K, Niemeyer D, Schneider H, Drosten C, Pohlmann S. 2011. Evidence that TMPRSS2 activates the severe acute respiratory syndrome coronavirus spike protein for membrane fusion and reduces viral control by the humoral immune response. J Virol 85:4122-4134. https://doi.org/10.1128/JVI.02232-10.

45. Shulla A, Heald-Sargent T, Subramanya G, Zhao J, Perlman S, Gallagher T. 2011. A transmembrane serine protease is linked to the severe acute respiratory syndrome coronavirus receptor and activates virus entry. J Virol 85:873-882. https://doi.org/10.1128/JVI.02062-10.

46. Simmons G, Gosalia DN, Rennekamp AJ, Reeves JD, Diamond SL, Bates P. 2005. Inhibitors of cathepsin $L$ prevent severe acute respiratory syndrome coronavirus entry. Proc Natl Acad Sci U S A 102:11876-11881. https://doi.org/10.1073/pnas.0505577102.

47. Iwata-Yoshikawa N, Okamura T, Shimizu Y, Hasegawa H, Takeda M, Nagata N. 2019. TMPRSS2 contributes to virus spread and immunopathology in the airways of murine models after coronavirus infection. J Virol 93:e01815-18. https://doi.org/10.1128/JVI.01815-18.

48. Kawase M, Shirato K, van der Hoek L, Taguchi F, Matsuyama S. 2012. Simultaneous treatment of human bronchial epithelial cells with serine and cysteine protease inhibitors prevents severe acute respiratory syndrome coronavirus entry. J Virol 86:6537-6545. https://doi.org/10.1128/ JVI.00094-12.

49. Zhou Y, Vedantham P, Lu K, Agudelo J, Carrion R, Jr, Nunneley JW, Barnard D, Pohlmann S, McKerrow JH, Renslo AR, Simmons G. 2015. Protease inhibitors targeting coronavirus and filovirus entry. Antiviral Res 116:76-84. https://doi.org/10.1016/j.antiviral.2015.01.011.

50. Follis KE, York J, Nunberg JH. 2006. Furin cleavage of the SARS coronavirus spike glycoprotein enhances cell-cell fusion but does not affect virion entry. Virology 350:358-369. https://doi.org/10.1016/j.virol.2006 .02.003.

51. Xia S, Liu M, Wang C, Xu W, Lan Q, Feng S, Qi F, Bao L, Du L, Liu S, Qin C, Sun F, Shi Z, Zhu Y, Jiang S, Lu L. 2020. Inhibition of SARS-CoV-2 (previously 2019-nCoV) infection by a highly potent pan-coronavirus fusion inhibitor targeting its spike protein that harbors a high capacity to mediate membrane fusion. Cell Res 30:343-355. https://doi.org/10 .1038/s41422-020-0305-x.

52. Kleine-Weber H, Elzayat MT, Hoffmann M, Pöhlmann S. 2018. Functional analysis of potential cleavage sites in the MERS-coronavirus spike protein. Sci Rep 8:16597. https://doi.org/10.1038/s41598-018-34859-w.

53. Park JE, Li K, Barlan A, Fehr AR, Perlman S, McCray PB, Jr, Gallagher T. 2016. Proteolytic processing of Middle East respiratory syndrome coronavirus spikes expands virus tropism. Proc Natl Acad Sci U S A 113: 12262-12267. https://doi.org/10.1073/pnas.1608147113.

54. Shirato K, Kanou K, Kawase M, Matsuyama S. 2017. Clinical isolates of human coronavirus $229 \mathrm{E}$ bypass the endosome for cell entry. J Virol 91:e01387-16. https://doi.org/10.1128/JVI.01387-16.

55. Shirato K, Kawase M, Matsuyama S. 2018. Wild-type human coronaviruses prefer cell-surface TMPRSS2 to endosomal cathepsins for cell entry. Virology 517:9-15. https://doi.org/10.1016/j.virol.2017.11.012.

56. Xia S, Zhu Y, Liu M, Lan Q, Xu W, Wu Y, Ying T, Liu S, Shi Z, Jiang S, Lu L. 11 February 2020. Fusion mechanism of 2019-nCoV and fusion inhibitors targeting HR1 domain in spike protein. Cell Mol Immunol https:// doi.org/10.1038/s41423-020-0374-2.

57. Baron SA, Devaux C, Colson P, Raoult D, Rolain JM. 2020. Teicoplanin: an alternative drug for the treatment of coronavirus COVID-19? Int J Antimicrob Agents 55:105944. https://doi.org/10.1016/j.ijantimicag.2020 .105944.

58. Zhang JM, Yu F, Liu J, Zou F, Pan T, Zhang H. 2020. Teicoplanin potently blocks the cell entry of 2019-nCoV. BioRxiv 20200205935387. https://doi .org/10.1101/2020.02.05.935387.

59. Wang M, Cao R, Zhang L, Yang X, Liu J, Xu M, Shi Z, Hu Z, Zhong W, Xiao G. 2020. Remdesivir and chloroquine effectively inhibit the recently emerged novel coronavirus (2019-nCoV) in vitro. Cell Res 30:269-271. https://doi.org/10.1038/s41422-020-0282-0.

60. Martinez MA. 2020. Compounds with therapeutic potential against novel respiratory 2019 coronavirus. Antimicrob Agents Chemother 64: e00399-20. https://doi.org/10.1128/AAC.00399-20.

61. Gautret $P$, Lagier JC, Parola P, Hoang VT, Meddeb L, Mailhe M, Doudier B, Courjon J, Giordanengo V, Vieira VE, Dupont HT, Honore S, Colson P, Chabriere E, La Scola B, Rolain JM, Brouqui P, Raoult D. 20 March 2020. Hydroxychloroquine and azithromycin as a treatment of COVID-19: results of an open-label non-randomized clinical trial. Int J Antimicrob Agents https://doi.org/10.1016/j.ijantimicag.2020.105949.

62. Zhu Y, Ding X, Yu D, Chong H, He Y. 2019. The tryptophan-rich motif of HIV-1 gp41 can interact with the N-terminal deep pocket site: new insights into the structure and function of gp41 and its inhibitors. J Virol 94:e01358-19. https://doi.org/10.1128/JVI.01358-19.

63. Zhang X, Ding X, Zhu Y, Chong H, Cui S, He J, Wang X, He Y. 2019. Structural and functional characterization of HIV-1 cell fusion inhibitor T20. AIDS 33:1-11. https://doi.org/10.1097/QAD.0000000000001979. 